\title{
Karaciğer Patolojilerinde Otoantikorların Klinik Tanıya Katkısının ve Eşlik Eden Otoimmün Hastalıkların Tanımlanmasındaki Rolünün Araştırılması
}

\section{Investigation of the Contribution of Autoantibodies to Clinical Diagnosis in Liver Pathologies and the Identification of Accompanying Autoimmune Diseases}

\author{
Ali DURAN ${ }^{1}($ ID), Alev ÇETIN DURAN²(ID), İsmail TAŞKIRAN³ (ID) \\ ${ }^{1}$ Balıkesir Üniversitesi Tıp Fakültesi, Genel Cerrahi Anabilim Dalı, Balıkesir. \\ ${ }^{1}$ Balıkesir University Faculty of Medicine, Department of General Surgery, Balıkesir, Turkey. \\ ${ }^{2}$ Balıkesir Atatürk Şehir Hastanesi, Tıbbi Mikrobiyoloji/Temel İmmünoloji Kliniği, Balıkesir. \\ 2 Balıkesir Atatürk City Hospital, Clinic of Medical Microbiology/Basic Immunology, Balıkesir, Turkey. \\ ${ }^{3}$ Aydın Adnan Menderes Üniversitesi Tıp Fakültesi, Gastroenteroloji Bilim Dalı, Aydın. \\ ${ }^{3}$ Aydın Adnan Menderes University Faculty of Medicine, Division of Gastroenterology, Aydın, Turkey.
}

Makale Atııı: Duran A, Çetin Duran A, Taşkıran i. Karaciğer patolojilerinde otoantikorların klinik tanıya katkısının ve eşlik eden otoimmün hastalıkların tanımlanmasındaki rolünün araştırılması. Mikrobiyol Bul 2022;56(1):81-94.

\section{ÖZ}

Otoantikorlar otoimmün karaciğer hastalıkları $(\mathrm{OKH})$ [otoimmün hepatit $(\mathrm{OIH})$, primer biliyer siroz (PBS), primer sklerozan kolanjit (PSK)] varlı̆ında sıkıkla tespit edilir ve hastalığı klinik olarak sınıflandırmak için yaygın olarak kullanılır. Bu çalışmada, otoantikorların OKH tanısına ve eşlik eden diğer sistemik otoimmün romatizmal hastalıklar (SORH)'ın belirlenmesine katkısını araştırmak amaçlanmıştır. Ayrıca. indirekt immünofloresan (IIF) yöntemi ile belirlenen antinükleer antikor (ANA) paternleri ile ekstrakte edilebilir nükleer antijen (ENA) antikorlarının karşılaştırılması da hedeflenmiştir. Çalışmaya Genel Cerrahi/ Gastroenteroloji Kliniklerinden karaciğer fonksiyon testi yüksekliği olan 544 hasta ve OKH araştırmak için Dahiliye/Romatoloji Kliniklerinden sevk edilen 49 hasta olmak üzere toplam 593 hasta dahil edilmiştir. Hastaların HBsAg ve anti-HCV test sonuçları negatif olarak belirlenmiştir. ANA, anti-mitokondriyal antikor (AMA)/anti-karaciğer-böbrek mikrozomal antikor (LKM), anti-düz kas antikor (ASMA), anti-nötrofil sitoplazmik antikor (ANCA) testleri IIF yöntemiyle çalışılmışır (Euroimmune AG, Luebeck, Almanya). ENA antikorları (nRNP/Sm, Sm, SS-A, SS-B, Scl-70, Jo-1, dsDNA, nükleozom, histon, ribozomal P-protein, AMA M2, Ro-52, PM-SCl, CENP-B, PCNA, DFS70) ve karaciğer profili [çözünür karaciğer antijeni/karaciğer pankreas antijeni (SLA/LP), karaciğer sitozolik antijen-1 (LC-1), LKM-1, anti-mitokondriyal antikor M2 (AMA-M2)] immünblot (IB) yöntemiyle (Euroimmune AG, Luebeck, Almanya) çalışıımıştır. Demografik özellikler, klinik veriler, sistemik otoimmün romatizmal hastalıkların (SORH) varlı̆̆ı, radyolojik ve laboratuvar bulguları; hastane tıbbi kayıtlarından elde edilmiştir. Beş yüz doksan üç hastanın (ortalama yaş= $53.3 \pm 15.6$, yaş aralığı $=18-90) 461(\% 77.7)^{\prime}$ inin otoantikor testleri negatif, $132(\% 22.3)^{\prime}$ sinin ise pozitif 
olarak saptanmıştır (\%86.4'ü kadın). Otoantikor pozitifliği saptanan hastaların \%60.6 (80/132)'sına PBS ve \%1.5 (2/132)'ine OiH (anti-LC-1 ve anti-LKM1 antikorları pozitif) tanısı konmuştur. Sentromer, nükleer membran (NM), çoklu nükleer noktalı (ÇNN) boyanma paternleri ve karaciğer enzim yüksekliği olan 14 (\%10.6) hastaya özgül bir hastalık tanısı konamamış ve takibe alınmıştır. SORH tanııı alan hastaların yaklaşık yarısında PBS (13/30) tespit edilmiştir. PBS tanısı alan hastalara en sık eşlik eden SORH, Sjögren sendromu (SS) (\%7.5, 6/80), daha sonra sirasiyla Romatoid artrit (RA) (\%5.0, 4/80), skleroderma (\%2.5, 2/80) ve sistemik lupus eritematozus (SLE) $(\% 1.3,1 / 80)$ olarak belirlenmiştir. Otoantikoru pozitif olan hastalarda en sık olarak AMA boyanma paterni (\%34.8, 46/132) belirlenmiştir. Hastaların \%31.1 (41/132)'inde AMA ve ANA boyanma paternleri birlikte saptanmıştır. Bu hastaların ENA profil sonuçlarına bakıldığında en sık olarak anti-Ro-52 (\%65.9, 27/41), daha sonra sırasıyla anti-SSA (\%34.1, 14/41), anti-SSB (\%22.0, 9/41), anti-CENP-B (\%12.2, 5/41) otoantikorları tespit edilmiştir. Hastaların \%32.6 (43/132)'sında (sırasıyla NM \%9.1, Sentromer \%9.1, ÇNN \%6.8) ANA paternleri saptanmıştır. Bu çalışmada PBS tanısı alan hastaların \%87.5 (70/80)'inde AMA pozitifliği, \%12.5 (10/80)'inde ise ANA pozitifliği (NM, ÇNN, sentromer, vb.) saptanmıştır. Tek başına AMA pozitifliği olan hastalar (Grup 1) ile çoklu patern/otoantikorları olan hastaların (Grup 2) özellikleri, laboratuvar ve radyolojik bulguları karşılaştııılmışırı. Çoklu paterni/ otoantikorları olan hastalarda (Grup 2) siroz varlığı ve karaciğer heterojenitesi Grup 1'e göre istatistiksel olarak anlamlı düzeyde yüksek bulunmuştur $(p=0.049)$. OKH ile ilişkili otoantikorlar, klinik hastalıktan yıllar önce tespit edilebilmektedir. OKH pek çok SORH ile birliktelik gösterebilir. SORH tanısı alan hastalarda $\mathrm{OKH}$ ile ilişkili otoantikorların tespiti sayesinde bu hastaların erken tanısı sağlanabilmektedir. Bu otoantikorlar, PBS`de olduğu gibi hem tanı hem de prognoz açısından da yol göstermektedir. Laboratuvar uzmanı ile klinisyen iş birliği bu hastaların tanısında, yönetiminde, klinik hastalık tablosu oluşmadan saptanmasında kritik öneme sahiptir.

Anahtar kelimeler: Otoimmün karaciğer hastalıkları; otoantikorlar; primer biliyer siroz; indirekt immünofloresan (IIF) yöntemi; immunblot (IB) yöntemi.

\section{ABSTRACT}

Autoantibodies are frequently detected in the presence of autoimmune liver diseases (ALD) [autoimmune hepatitis (AIH), primary biliary cirrhosis (PBC), primary sclerosing cholangitis (PSC)] and are widely used to classify the disease clinically. The aim of this study was to investigate the contribution of autoantibodies for the diagnosis of ALD and the identification of other accompanying systemic autoimmune rheumatic diseases (SARD). In addition, it was aimed to compare the results of indirect immunofluorescence (IIF) antinuclear antibody (ANA) patterns and extractable nuclear antigen (ENA) antibodies. A total of 593 patients, including 544 patients with high liver function tests from general surgery/gastroenterology clinics and 49 patients referred from internal medicine/rheumatology clinics to investigate ALD, were included in the study. $\mathrm{HBsAg}$ and anti-HCV test results of the patients were found to be negative. ANA, anti-mitochondrial antibody (AMA)/anti-liver-kidney microsomal antibody (LKM), anti-smooth muscle antibody (ASMA), antineutrophil cytoplasmic antibody (ANCA) assays were performed by indirect immunofluorescence method (IIF) (Euroimmune AG, Luebeck, Germany). Extractable nuclear antigen (ENA) (nRNP/Sm, Sm, SS-A, SS-B, Scl-70, Jo-1, dsDNA, nucleosome, histone, ribosomal P-protein, AMA-M2, Ro-52, PM-Scl, CENP-B, PCNA, DFS70) and liver profiles [soluble liver antigen \liver pancreas antigen (SLA/LP), liver cytosolic antigen1(LC-1), LKM-1, anti-mitochondrial antibody M2(AMA-M2)] (Euroimmune AG, Luebeck, Germany) were detected by immunoblot (IB) method. Demographic characteristics, clinical data, presence of systemic autoimmune rheumatic diseases (SARD), radiological and laboratory findings were determined from the medical records. Autoantibody tests were found to be negative in $461(77.7 \%)$ of 593 patients (mean age $=53.3 \pm 15.6$, age range $=18-90)$, and were positive in $132(22.3 \%)(86.4 \%$ female $)$ of the patients. Of the patients with positive autoantibodies, $60.6 \%(80 / 132)$ were diagnosed as PBS and $1.5 \%(2 / 132)$ were diagnosed as AlH (positive anti-LC-1 and anti-LKM1 antibodies). Fourteen of the patients (10.6\%) with centromere, nuclear membrane (NM), multiple nuclear dot (MND) staining patterns and elevated liver enzymes could not be diagnosed as a specific disease and were followed up. PBS (13/30) was detected in approximately half of the patients diagnosed with SARD. The most common accompanying SARD in PBC patients was Sjögren's syndrome (SS) $(7.5 \%, 6 / 80)$, followed by rheumatoid arthritis (RA) $(5.0 \%$, $4 / 80)$, scleroderma $(2.5 \%, 2 / 80)$, and systemic lupus erythematosus (SLE) $(1.3 \%, 1 / 80)$ respectively. The most common pattern was the AMA staining pattern $(34.8 \%, 46 / 132)$ among the autoantibody positive patients. AMA and ANA staining patterns were detected together in $31.1 \%(41 / 132)$ of the patients. In the 
ENA profile results of these patients, the most common profile detected was anti-Ro-52 $(65.9 \%, 27 / 41)$, followed by anti-SSA $(34.1 \%, 14 / 41)$, anti-SSB $(22.0 \%, 9 / 41)$ and anti-CENP-B $(12.2 \%, 5 / 41)$ autoantibodies, respectively. ANA patterns were detected in 32.6\% (43/132) of the patients (NM 9.1\%, centromere 9.1\%, MND 6.8\%, respectively). In our study, $87.5 \%(70 / 80)$ of the patients diagnosed as PBS were found to have AMA positivity and $12.5 \%(10 / 80)$ of them had ANA positivity (such as NM, CNN, centromere). The characteristics, laboratory and radiological findings of the patients with isolated AMA positivity alone (Group 1) and patients with multiple patterns/autoantibodies (Group 2) were compared. In patients with multiple patterns/autoantibodies (Group 2), the presence of cirrhosis and liver heterogeneity were found to be higher than Group $1(p=0.049)$. ALD associated autoantibodies can be detected before years from the clinical disease. ALD may be associated with various SARD. Detection of ALD-related autoantibodies in patients diagnosed with SARD can provide early diagnosis of these patients. These autoantibodies guide both diagnosis and prognosis as in PBC. Collaboration between the laboratory specialist and the clinician is critical in the diagnosis, management and early recognition of these patients before clinical disease.

Keywords: Autoimmune liver diseases; autoantibodies; primary biliary cirrhosis; indirect immunofluorescence (IIF) method; immunoblot (IB) method.

\section{Giriş}

Otoimmün karaciğer hastalıkları (OKH) olan otoimmün hepatit (OiH), primer biliyer siroz (PBS) ve primer sklerozan kolanjit (PSK) tablolarında çeşitli derecelerde immün-aracılı karaciğer hasarı oluşmaktadır. PBS ve PSK kolestatik otoimmün karaciğer bozukluğu iken, OiH'de hepatosit hasarı ile giden hepatit tablosu ön plandadır. Otoantikorlar, OKH varlığında sıkıkla saptanır ve hastalığı klinik olarak sınıflamak için yaygın olarak kullanılır ${ }^{1}$.

Tip-I OiH'de, anti-nükleer antikor (ANA) ve/veya anti-düz kas antikorları (ASMA), tip-II OiH'de anti-karaciğer böbrek mikrozomal antijen tip-1 (anti-LKM-1), anti-karaciğer sitozolik antijen tip-1 (anti-LC-1) antikorları tanımlanmışır. "Anti-soluble liver antigen \liver pancreas antigen" (anti-SLA LP) antikorları ise tip III OiH'de saptanmaktadır ${ }^{1,2}$.

PSK'de periferik anti-nötrofil sitoplazmik antikor (p-ANCA) (\%26-94), ANA (\%8-77) ve ASMA (\%83'e kadar değişen oranlarda) otoantikor reaktivitesi görülmektedir ${ }^{3}$. PBS, klasik olarak 40 yaşın üzerindeki kadınlarda görülür, anti-mitokondriyal antikor (AMA) prevelansı $\% 90$ 'dan fazladır ve bu durum klinik semptomlardan çok önce ortaya çıkabilir. PBS'li kişilerin \%30-50'sinde ANA pozitifliği de saptanabilmektedir ve bu durum genellikle antijene özgüldür (anti-gp210, anti-sp100 gibi) ${ }^{2,4}$. ANA pozitifliği HEp-2 hücrelerinde çoklu nükleer noktalı (ÇNN) boyanma veya nükleer membran (NM) boyanma paternleri ile karakterizedir. Ayrıca antisentromer antikor (ASA) pozitifliği de saptanabilmektedir ${ }^{4}$.

Otoimmün karaciğer hastalıklarında semptomlar çok özgül değildir ve yorgunluk, miyalji, artralji, karın ağrısı, kaşıntı, sarılık gibi semptomlarla karşımıza çıkmaktadır. Karaciğer fonksiyon testlerinde (KCFT) yükseklik önemli bir bulgudur. OKH diğer otoimmün hastalıklarla birliktelik gösterebilir2,5. Bu nedenle OKH saptandığında eşlik edebilecek diğer otoimmün hastalıkların olabileceği akılda tutulmalıdır.

Bu çalışmada otoantikorların OKH tanısına ve eşlik eden diğer sistemik otoimmün romatizmal hastalıkların (SORH) tanımlanmasına katkısının araşıııııması amaçlanmışır. Ayrıca indirekt immünfloresan (IIF) yöntemi ile belirlenen ANA paternleri ile ekstrakte edilebilir nükleer antijen (ENA) antikorlarının karşısş̧ııııması da hedeflenmiştir. 


\section{GEREÇ ve YÖNTEM}

Bu çalışma, Balıkesir Üniversitesi Girişimsel Olmayan Araştırmalar Etik Kurulu onayı ile gerçekleştirildi (Tarih: 10.06.2020 ve Karar No: 2020/89).

2017-2019 yılları arasında genel cerrahi, gastroenteroloji klinikleri tarafından, KCFT bozukluğu olan 544 hasta ve dahiliye/romatoloji kliniklerinden $\mathrm{OKH}^{\prime}$ nin araştırılması amacıyla sevk edilen 49 hasta olmak üzere toplam 593 hasta çalışmaya dahil edildi. Hastaların HBsAg ve anti-HCV test sonuçları negatif olarak belirlendi. ANA, AMA/anti-LKM, ASMA, ANCA testleri IIF yöntemle, ENA antikorları ve karaciğer profili ise immünblot (IB) yöntemiyle çalışıldı.

Hastaların demografik özellikleri (yaş, cinsiyet vb.), biyokimyasal testleri [alanin aminotransferaz (ALT), aspartat aminotransferaz (AST), gama-glutamil transpeptidaz (GGT), alkalen fosfataz (ALP), total bilirubin], radyolojik inceleme sonuçları, belirti-bulguları ve SORH varlığı gibi klinik verileri hastane kayıtlarından elde edildi.

\section{İndirekt İmmünfloresan Testler (IIF)}

ANA, AMA/LKM, ASMA otoantikorları HEp-20/10, karaciğer, mide ve böbrek substratlarının olduğu ticari kitle (Euroimmun AG, Luebeck, Almanya) IIF yöntemle tespit edildi ANA IIF paternleri, ICAP standartlarına göre belirlendi (www.ANApatterns.org).

ANCA tespiti için etanolle fikse nötrofiller, formaldehitle fikse nötrofiller, HEp-2, miyeloperoksidaz (MPO), proteinaz 3 (PR3) içeren slaytlar (Euroimmun AG, Granülosit Mosaic, Almanya) kullanıldı.

\section{İmmünblot Yöntemi}

\section{ENA Profil}

Bu çalışmada ekstrakte edilebilir nükleer antijenlere (ENA) karşı antikorlar EUROLINE ANA Profil 3 plus DFS70 (lgG) test kiti (Euroimmune AG, Luebeck, Almanya) ile araştırıldı. İmmünoblot stripleri 16 ayrı antijen (nRNP/Sm, Sm, SS-A, SS-B, Scl-70, Jo-1, dsDNA, nükleozom, histon, ribozomal P-protein, AMA M2, Ro-52, PM-Scl, CENP-B, PCNA ve DFS70) içermektedir. EUROBlotOne sistemi (Euroimmun) ile tüm inkübasyon ve yıkama basamakları otomatik olarak gerçekleştirildi. Bant yoğunlukları EUROLineScan yazılımı (Euroimmun) kullanılarak değerlendirildi.

\section{Karaciğer Profili}

Anti-SLA \LP, anti-LC-1, anti-LKM-1 ve AMA-M2 antikorları, immünoblot yöntemi ile karaciğer profil kiti (Euroimmune AG, Luebeck, Almanya) kullanılarak araştırıldı.

\section{İstatistiksel Analiz}

Çalışmada elde edilen veriler SPSS 22.0 (SPSS INC, Chicago, IL, ABD) programına kaydedildi ve istatistiksel analizleri yapıldı. Gruplardan en az biri normal dağılıma uymadığı için sayısal verilerde bağımsız iki grubun karşılaştırılmasında Mann-Whitney U testi kulla- 
nıldı. Kategorik değişkenler yüzde ve ortalama \pm standart sapma olarak verildi. Kategorik değişkenlerin bulunduğu bağımsız grupların karşılaştırılmasında ki-kare testi kullanıldı. p değerinin 0.05 'in altında olduğu durumlar istatistiksel olarak anlamlı sonuçlar olarak değerlendirildi.

\section{BULGULAR}

Çalışma grubundaki 593 hastanın (ortalama yaş= $53.3 \pm 15.6$, yaş aralığı= 18-90) 461 (\%77.7)'inin otoantikor testleri negatif, 132 (\%22.3)'sinin ise pozitif saptanmıştır (\%86.4'ü kadın) (Tablo I).

Genel cerrahi ve gastroenteroloji kliniklerinden KCFT'de yükseklik nedeniyle otoantikor tayini için gönderilen 544 hastanın 83 (\%15.3)'ünde otoantikor pozitifliği saptanmıştır. Ayrıca dahiliye/romatoloji kliniklerinden SORH tanısıyla birlikte AMA-M2 otoantikoru belirlenen ve NM, ÇNN, sentromer boyanma paternleri olan toplam 49 hasta OKH araştırılması açısından Gastroenteroloji Kliniğine sevk edilmiştir (Tablo II).

Otoantikor pozitifliği saptanan hastaların \%60.6'sına (80/132) PBS ve \%1.5'ine (2/132) OïH tanısı konmuştur. Sentromer, NM, ÇNN boyanma paternleri ve KCFT yüksekliği olan 14 hastaya (\%10.6) özgül bir hastalık tanısı konamamış ve takibe alınmıştır. Bu hastaların ortalama iki yıllık takiplerinde OKH gelişmemiştir (Tablo II).

Dahiliye/romatoloji kliniklerinden sevk edilen hastaların 30 (30/49)'u SORH tanısı almıştır. SORH tanısı olan hastaların yaklaşık yarısına PBS tanısı (13/30) konmuştur. PBS tanısı alan hastalara en sık eşlik eden SORH, Sjögren sendromu (SS) (\%7.5, 6/80), daha sonra sırasıyla romatoid artrit (RA) (\%5.0, 4/80), skleroderma (\%2.5, 2/80) ve sistemik lupus eritematozus (SLE) (\%1.3, 1/80) olarak belirlenmiştir. SORH tanısı olmayan ve NM, ÇNN, sentromer boyanma paternleri olan 19 hastada (19/49) ilk başvuruda ve takiplerde OKH saptanmamıştır. Buna karşın SORH tanısı olan ve SORH ilişkili otoantikorlarla birlikte AMA-M2, NM, sentromer gibi otoantikorların eşlik ettiği, başlangıçta OKH saptanmayan 17 hastanın ortalama iki yıllık takiplerinde 14 hastada OKH gelişmezken üç hastada PBS gelişmiştir (Tablo II). Çalışmamızda takibe alınan hastalar içinde SORH olan üç hastada $(\mathrm{SS}=2, \mathrm{RA}+\mathrm{SS}=1)$ ortalama 13.3 aylık bir süre içinde (12-15 ay arasında) PBS geliştiği görülmüştür. Klinik bulgu ve KCFT yüksekliği olan bu hastalarda siroz saptanmamış ve

\begin{tabular}{lccc}
\hline \multicolumn{4}{|l}{ Tablo I. Otoantikor Testleri Çalısılan Hastaların Yaş ve Cinsiyet Özellikleri } \\
\hline $\begin{array}{l}\text { Otoantikor negatif } \\
\text { Özellikler }\end{array}$ & $\begin{array}{c}\text { Otoantikor pozitif } \\
\mathbf{n}(\%)\end{array}$ & \multicolumn{1}{l}{ Toplam } \\
\hline Sayı & $461(77.7)$ & $132(22.3)$ & $593(100.0)$ \\
Yaş (Ort \pm SD) & $52.5 \pm 16.3(18-90$ yaş) & $56.1 \pm 12.8(19-85$ yaş) & $53.3 \pm 15.6(18-90$ yaş) \\
Cinsiyet & & & \\
Kadın & $296(64.2)$ & $114(86.4)$ & $410(69.1)$ \\
Erkek & $165(35.8)$ & $18(13.6)$ & $183(30.9)$ \\
Kadın/Erkek & 1.7 & 6.3 & 2.2 \\
\hline Ort: Ortalama, SD: Standart sapma. & & \\
\hline
\end{tabular}




\begin{tabular}{|c|c|c|c|c|c|}
\hline & $\begin{array}{c}\text { Otoantikor } \\
(+)\end{array}$ & PBS & $\mathrm{OIH}$ & $\begin{array}{c}\text { KCFT } \\
\text { yüksekliği }\end{array}$ & Karaciğer hastalığı yok* \\
\hline $\begin{array}{l}\text { Genel Cerrahi/ } \\
\text { Gastroenteroloji } \\
(\mathrm{n}=544)\end{array}$ & $83(62.9)$ & $67(50.8)$ & $2(1.5)$ & $\begin{array}{l}14 \text { (10.6) } \\
\text { (NM/ÇNN/ } \\
\text { Sentromer) }\end{array}$ & - \\
\hline \multicolumn{6}{|l|}{$\begin{array}{l}\text { Dahiliye/ } \\
\text { Romatoloji }(n=49)\end{array}$} \\
\hline SORH yok $(n=19)$ & $19(14.4)$ & - & - & - & $\begin{array}{c}19 \text { (14.4) } \\
\text { (NM/ÇNN/Sentromer) }\end{array}$ \\
\hline SORH $\operatorname{var}(n=30)$ & $30(22.7)$ & $13(9.8)$ & - & - & $\begin{array}{l}17(12.9) \\
\text { (AMA-M2/NM/Ek otoantikor) }\end{array}$ \\
\hline SS & $18(13.6)$ & $6(4.5)$ & & & $\underline{12^{\star \star}}(9.1)$ \\
\hline RA & $5(3.8)$ & $4(3.0)$ & & & $1(0.8)$ \\
\hline SSc & $3(2.3)$ & $2(1.5)$ & & & $1(0.8)$ \\
\hline SS+RA & $2(1.5)$ & - & & & $\underline{2^{* *}}(1.5)$ \\
\hline SLE & $2(1.5)$ & $1(0.8)$ & & & $1(0.8)$ \\
\hline Toplam & $132(100.0)$ & $80(60.6)$ & $2(1.5)$ & $14(10.6)$ & $36(27.3)$ \\
\hline \multicolumn{6}{|c|}{$\begin{array}{l}\text { **ilk değerlendirmede PBS tanısı olmayan toplam üç hastaya }(S S=2, S S+R A=1) \text { takiplerde klinik ve laboratuvar } \\
\text { bulgular ile PBS tanısı konmuştur. }\end{array}$} \\
\hline \multicolumn{6}{|c|}{$\begin{array}{l}\text { PBS: Primer biliyer siroz, OIH: Otoimmün hepatit, KCFT: Karaciğer fonksiyon testleri, NM: Nükleer membran, } \\
\text { ÇNN: Çoklu Nükleer Noktalı boyanma, AMA: Antimitokondriyal antikor, SORH: Sistemik Otoimmün Romatizma } \\
\text { Hastalık, SS: Sjögren sendromu, RA: Romatoid artrit, SSc: Skleroderma, SLE: Sistemik lupus eritematozus, AMA } \\
\text { Antimitokondriyal antikor, NM: Nükleer membran, ÇNN: Çoklu nükleer noktalı. }\end{array}$} \\
\hline
\end{tabular}

ursodeoksikolik asit (UDKA) tedavisine başlanmıştır. Bu üç hastanın cinsiyeti kadın olup (ortalama yaş= $53.67 \pm 17.93$ ) iki hastada SS, bir hastada RA+SS birlikteliği görülmüştür.

SS tanısı olan 18 hastanın \%94.4 (17/18)'ünde anti-Ro52 antikoru belirlenmiş, \%61.1 $(11 / 18)^{\prime}$ inde ise anti-Ro52 ile anti-SSA birlikteliği saptanmıştır. SS hastalarının \%33.3 (6/18)'ünde ilk başvuruda PBS saptanmış ve bunların yarısında siroz gelişmiştir. Ortalama 13.3 aylık sürede (12-15 ay arasında) PBS gelişen iki SS hastasının ENA profilinde AMA-M2, Ro52, SSA, SSB; RA + SS olan bir hastanın ENA profilinde AMA-M2, Ro52 hedef antijenler olarak belirlenmiştir.

PBS tanısı alan hastalara UDKA tedavisi başlanmıştır. Hastalar radyolojik tetkikler, biyokimyasal testler ve klinik izlem için 3-6 ayda bir takibe çağrılmıştır.

Otoantikor pozitif olarak saptanan hastalarda en sık olarak AMA boyanma paterni (\%34.8, 46/132) belirlenmiştir. Hastaların \%31.1 (41/132)'inde AMA ve ANA boyanma paternleri birlikte saptanmıştır. AMA boyanma paternine en sık eşlik eden paternler sırasıyla granüler patern (\%68.3, 28/41), sentromer (\%12.2, 5/41), NM (\%7.3, 3/41), ÇNN (\%4.9, 2/41), homojen (\%2.4, 1/41), NM-DFS (\%2.4, 1/41) ve NM-ÇNN (\%2.4, 1/41) paternleri olarak belirlenmiştir. Bu hastaların ENA profil sonuçlarına en sık anti-Ro-52 


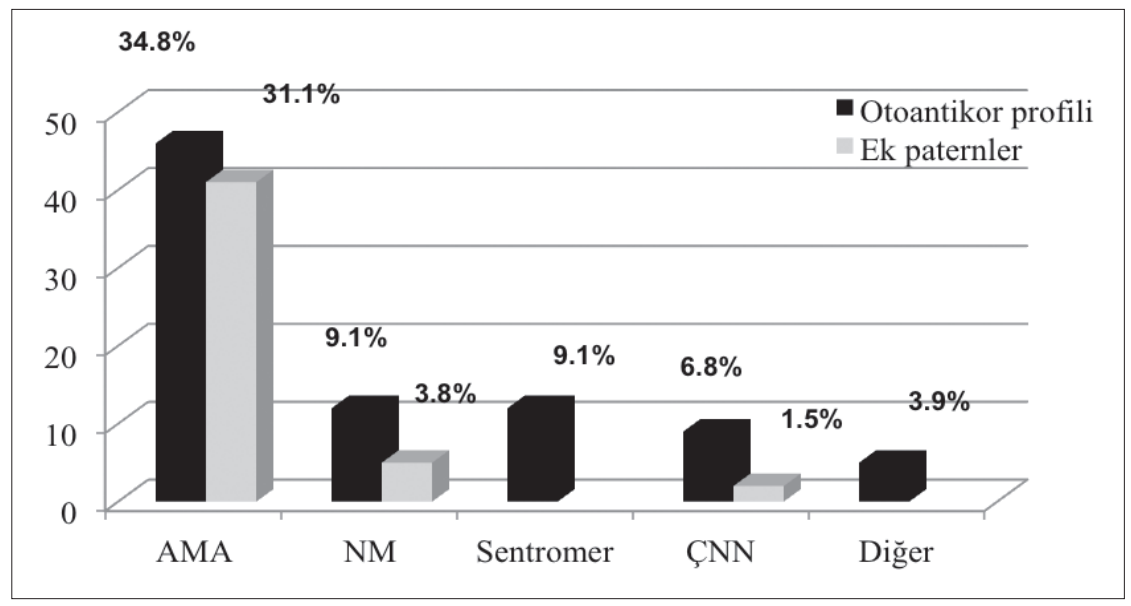

Şekil 1. Otoantikor profillerinin dağılımı.

AMA: Antimitokondriyal antikor, NM: Nükleer membran, ÇNN: Çoklu nükleer noktalı.

(\%65.9, 27/41), daha sonra sırasıyla anti-SSA (\%34.1, 14/41), anti-SSB (\%22.0, 9/41), anti-CENP-B (\%12.2, 5/41) otoantikorları tespit edilmiştir (Şekil 1 ve Tablo III).

Hastaların \%32.6 (43/132)'sında ANA paternleri saptanmıştır (en sık NM \%9.1, Sentromer \%9.1, ÇNN \%6.8). Karaciğer profil testinde birer hastada OIH ile ilişkili otoantikorlar olan LC-1 (\%0.8) ve LKM-1 (\%0.8) otoantikorları tespit edilmiştir (Şekil 1 ve Tablo III).

Anti-Ro52 antikoru pozitif PBS hastaları ile anti-Ro52 negatif PBS hastaları klinik bulgular, yaş, cinsiyet, biyokimyasal testler (ALT, AST, ALP, GGT, bilirubin), radyolojik bulgular (karaciğer heterojenitesi) ve siroz varlığı açısından karşılaştırılmış ve iki grup arasında istatistiksel olarak anlamlı bir fark saptanmamıştır [sırasıyla $p=0.784, p=0.390, p=0.728, p=$ $0.770, p=0.660, p=0.167, p=0.435, p=0.384, p=0.384]$.

Tek başına AMA pozitifliği olan hastalar (Grup 1) ile çoklu patern/otoantikorları olan hastaların (Grup 2) özellikleri, laboratuvar ve radyolojik bulguları karşılaştırılmıştır. Çoklu paterni/otoantikorları olan hastalarda (Grup 2) siroz varlığı ve USG'de karaciğer heterojenitesi Grup 1'e göre istatistiksel olarak anlamlı düzeyde yüksek bulunmuştur $(p=0.049)$ (Tablo IV).

\section{TARTIŞMA}

Otoimmün karaciğer hastalıklarının prevalansına bakıldığında en sık PBS (milyonda 400 olgu) karşımıza çıkmaktadır. OIH milyonda 100 olgu ve PSK milyonda 150 olgu prevalansa sahiptir ${ }^{5}$. Çalışmamızda OKH açısından araştırılan hastaların \%22.3'ünde (ortalama yaş= $56.1 \pm 12.8$ ) otoantikor testlerinde pozitiflik saptanmış (\%86.4'ü kadın) (Tablo I) ve literatürle uyumlu şekilde en sık PBS tanısı (\%60.6) konulmuştur ${ }^{5}$. Sentromer, NM, ÇNN boyanma paternleri ve KCFT yüksekliği olan 14 hastaya (\%10.6) özgül bir hastalık tanısı konulmamış ve takibe alınmıştır. Bu hastaların ortalama iki yıllık takiplerinde 


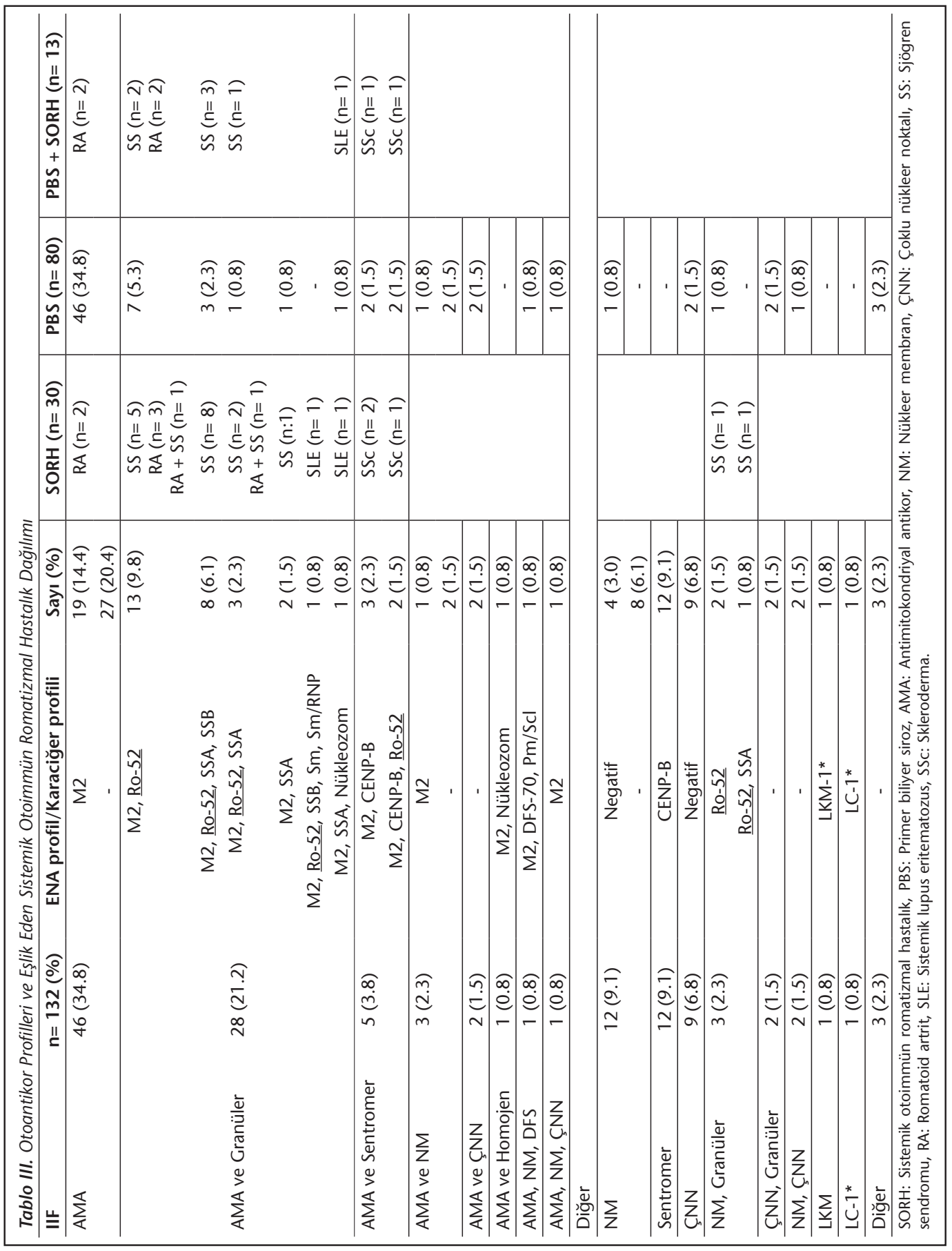




\begin{tabular}{|c|c|c|c|c|}
\hline Primer Biliyer Siroz & Sayı (\%) $(n=75)$ & $\begin{array}{c}\text { Grup } 1(n=46) \\
\text { (izole AMA pozitifliği) }\end{array}$ & $\begin{array}{l}\text { Grup } 2(\mathrm{n}=29) \\
\text { (Çoklupaternler) }\end{array}$ & $\mathbf{p}$ \\
\hline $\begin{array}{l}\text { Ortalama yaş } \pm \text { SD (yaş } \\
\text { aralığı) }\end{array}$ & $\begin{array}{l}57.92 \pm 11.18 \\
(25-85 \text { yaş })\end{array}$ & $\begin{array}{l}56.89 \pm 11.85 \\
(25-80 \text { yaş })\end{array}$ & $\begin{array}{l}59.55 \pm 10.01 \\
(40-85 \text { yaş })\end{array}$ & 0.462 \\
\hline \multicolumn{5}{|l|}{ Cinsiyet } \\
\hline Kadın & $66(88.0)$ & $38(50.7)$ & $28(37.3)$ & 0.070 \\
\hline Erkek & $9(12.0)$ & $8(10.7)$ & $1(1.3)$ & \\
\hline \multicolumn{5}{|l|}{ Siroz varlığı } \\
\hline Siroz var & $26(34.7)$ & $12(16.0)$ & $14(18.7)$ & 0.049 \\
\hline Siroz yok & $49(65.3)$ & $34(45.3)$ & $15(20.0)$ & \\
\hline $\begin{array}{l}\text { USG: Karaciğer hetero- } \\
\text { jenitesi }\end{array}$ & $26(34.7)$ & $12(16.0)$ & $14(18.7)$ & 0.049 \\
\hline \multicolumn{5}{|l|}{$\begin{array}{l}\text { Laboratuvar Değerleri } \\
\text { (ort. } \pm S D \text { ) }\end{array}$} \\
\hline $\operatorname{ALT}(\mathrm{U} / \mathrm{L})$ & $36.12 \pm 28.27$ & $39.00 \pm 31.89$ & $31.39 \pm 20.71$ & 0.394 \\
\hline AST (U/L) & $39.29 \pm 24.71$ & $38.84 \pm 21.39$ & $40.00 \pm 29.70$ & 0.499 \\
\hline ALP (U/L) & $192.26 \pm 128.67$ & $190.47 \pm 138.25$ & $195.14 \pm 113.98$ & 0.451 \\
\hline GGT (U/L) & $121.38 \pm 114.99$ & $116.18 \pm 92.33$ & $129.75 \pm 145.77$ & 0.500 \\
\hline Bilirübin (mg/dl) & $0.79 \pm 0.57$ & $0.81 \pm 0.60$ & $0.76 \pm 0.53$ & 0.654 \\
\hline
\end{tabular}

SD: Standart sapma, USG: Ultrasonografi, ALT: Alanin aminotransferaz, AST: Aspartat aminotransferaz, ALP: Alkalen fosfataz, GGK: Gama-glutamil transpeptidaz.

OKH gelişmediği görülmüştür. Dahiliye/romatoloji kliniklerinden sevk edilen SORH tanısı olmayan ve OKH ile ilişkili olabilecek otoantikorlar olan NM, ÇNN, sentromer boyanma paternleri belirlenen 19 hastada (\%14.4) ilk başvuruda ve takiplerde OKH saptanmamıştır. Buna karşın SORH tanısı olan (en sık SS \%9.1) ve SORH ilişkili otoantikorlarla birlikte AMA-M2, NM, sentromer gibi otoantikorların eşlik ettiği, başlangıçta OKH saptanmayan 17 hastanın (\%12.9) ortalama iki yıllık takiplerinde 14 hastada OKH gelişmezken üç hastada PBS gelişmiştir (Tablo II). Bu üç hastanın cinsiyeti kadın olup (ortalama yaş= 53.67 \pm 17.93) iki hastada SS, bir hastada RA + SS birlikteliği saptanmıştır. SS olan hastaların ENA profilinde AMA-M2, Ro52, SSA, SSB, RA + SS olan hastanın ENA profilinde AMA-M2, Ro52 hedef antijenler olarak saptanmıştır. OKH ile ilişkili otoantikorlar hastalıktan yıllar önce saptanabilmektedir. Klinik bulgular daha sonra ortaya çıkabilmektedir ${ }^{6,7}$. Bu nedenle bu hastaların takibi son derece önemlidir.

Primer SS'de OKH'yi tahmin etmek için serolojik belirteçler olarak otoantikorların klinik öneminin değerlendirildiği bir çalışmada, beş yıllık takip sonucunda AMA pozitifliği olan hastaların çoğunun semptomatik PBS geliştirdiği bildirilmiştir ${ }^{8}$. Çalışmamızda otoantikor pozitifliği olan hastaların \%13.6 (18/132)'sında SS tanısı olup bunların üçte birinde ilk başvuruda PBS saptanmıştır, iki yıllık takipte iki SS hastasında ve RA + SS birlikteliği olan bir hastada siroz olmaksızın, klinik bulgu ve KCFT yüksekliği ile PBS tanısı konmuştur. 
Csepregi ve arkadaşlarının çalışmasıyla ${ }^{8}$ benzer olarak, çalışmamızda SS tanısı alan hastaların \%44.4 (8/18)'ünde PBS hastalığa eşlik etmiştir. Otoantikor pozitifliği olup klinik, laboratuvar ve radyolojik bulgusu olmayan bu hastaların takibi, siroz gelişmeden PBS tanısı koyup tedaviye başlanması için önemli bir basamaktır.

Otoantikorların gelişimi, otoimmün hastalıkların klinik belirtilerinden önce meydana gelmektedir $^{6,7}$. Otoantikorların hastalığın başlangıcından çok önce ortaya çıkabileceğini gösteren ilk önemli veriler, SLE için bildirilmiştir ve bu gecikme süresinin sekiz yıla kadar uzayabileceği vurgulanmıştır ${ }^{6,9}$. Belirtilen bu uzun latens süresi hipotezinin PBS, RA, Tip 1 DM başta olmak üzere diğer birçok otoimmün hastalıkta da meydana geldiği saptanmıştır6 ${ }^{6}$ PBS için bu sürenin 0.9-19 yıl arasında olabileceği bildirilmektedir ${ }^{9-11}$. İlk olarak 1986،da Mitchison ve arkadaşları AMA pozitif olan ancak KCFT normal ve karaciğer hastalığı bulgusu olmayan 29 hasta belirlemiştir ${ }^{12}$. Bu hastaları 10 yıl boyunca izlemiş ve \%76'sının PBS açısından semptomatik hale geldiğini gözlemişlerdir. Bu çalışma, herhangi bir klinik veya biyokimyasal bulgu ortaya çıkmadan önce, AMA pozitif olan bireylerin zaman içerisinde PBS olabileceklerini doğrulamaktadır ${ }^{10}$. Çalışmamızda da ortalama 13.3 aylık bir süre içinde (12-15 ay arasında) AMA-M2 pozitif iki SS ve bir SS + RA tanısı olan hastada PBS gelişmiştir. Takip süresi uzadıkça bu sayı daha da artabilir. Yıllar içinde biyokimyasal ve klinik olarak belirgin hastalık gelişiminde etkili olan faktörler tam olarak bilinmese de bakteriyel enfeksiyonlar, ilaçlar, beslenme şekli, ksenobiyotikler, sigara gibi çevresel etkenlerin rolü üzerinde durulmaktadır ${ }^{6}$. Genetik faktörlerin yanı sıra ek otoimmün hastalıkların varlığı ve sigara PBS gelişimi için en önemli faktörler olarak belirlenmiştir ${ }^{13}$. Çalışmamızda da takibe alınan hastalar içinde SORH tanısı olan üç hastada $(S S=2, R A+$ SS= 1) PBS geliştiği görülmüştür.

Tüm bu çalışmalar klinik bulgu olmadan saptanan otoantikorların hastalık gelişimi açısından bir tarama testi olarak kullanılıp kullanılmayacağı sorusunu akla getirmektedir. PBS için AMA pozitifliğinin, hastalığı erken dönemde yakalamaya, tedavinin daha erken başlanmasına ve hastalığın ilerlemesinin önüne geçmede etkili olabileceğini düşündürmektedir. Bu nedenle bu tür erken öngörü belirteçlerinin belirlenmesi, birçok araştırma grubu için önemli bir odak noktası haline gelmiştir ${ }^{6}$. Bu hastaların erken dönemde saptanması ve $\mathrm{OKH}$ açısından yakın takibi, morbidite ve mortaliteyi önemli ölçüde azaltacaktır. Bu anlamda farklı klinikler arası iletişim, laboratuvar sonuçlarının doğru yorumu, laboratuvar uzmanı tarafından yönlendirme son derece önemlidir.

Çalışmamızda SORH tanısı olan hastaların yaklaşık yarısına PBS tanısı konmuştur. PBS hastalarının \%16.3 (13/80)'ünde SORH belirlenmiştir. PBS tanısı alan hastalara en sık eşlik eden SORH, SS $(\% 7.5 ; 6 / 80)$, daha sonra sırasıyla RA (\%5.0; 4/80), SSC (\%2.5; 2/80) ve SLE (\%1.3; 1/80) olarak belirlenmiştir (Tablo II). Uluslararası 20 merkezden 1554 PBS hastasının incelendiği çalışmada ${ }^{14}$, bu hastalarda SORH arasında en sık SS (\%8.3), sonra sırasıyla SSc (\%2.9), RA (\%2.7) ve SLE (\%1.7) saptanmıştır. OKH olan hastaların yaklaşık \%20'sinde otoimmün romatizmal hastalıklar bulunmaktadır. Bu nedenle birliktelik gösteren bu hastalıkların erken bir aşamada, özellikle preklinik dönemde otoantikorların tespiti sayesinde tanımlanması çok önemlidir ${ }^{15}$. OIH hastalarının \%20-50'sine otoimmün tiro- 
idit, diyabet, RA ve ülseratif kolit başta olmak üzere ekstrahepatik otoimmün hastalıklar eşlik etmektedir ${ }^{16}$. OIH ve SLE birlikteliği \%2.7-20, OIH ve SS birlikteliği \%6-47 oranında bildirilmektedir $^{5,17-21}$. PSK'nin otoimmün romatizmal hastalıklarla birlikteliği nadir bildirilmiştir fakat enflamatuvar bir bağırsak hastalığı olan ülseratif kolitle birlikteliği sıktır ${ }^{5}$. PBS tanısı alan hastaların yaklaşık üçte birinin başka bir otoimmün hastalığa sahip olduğu kabul edilmektedir ${ }^{22}$. Çalışmalarda PBS ve SLE birlikteliği \%2.7-15, PBS ve SS birlikteliği \%35-57, PBS ve SSc birlikteliği ise \%51.2 oranında bildirilmiştir 5,17-21,23,24.

Çalışmamızda otoantikor pozitifliği saptanan hastalarda en sık olarak AMA boyanma paterni $(\% 34.8,46 / 132)$ belirlenmiştir. Hastaların \%31.1 (41/132)'inde AMA ve ANA boyanma paternleri birlikte saptanmıştır [En sık granüler patern (\%68.3, 28/41), sonra sırasıyla sentromer (\%12.2, 5/41), NM (\%7.3, 3/41), ÇNN (\%4.9, 2/41)]. Bu hastaların ENA profil sonuçlarına bakıldığında en sık anti-Ro-52 (\%65.9, 27/41), daha sonra sırasıyla anti-SSA (\%34.1, 14/41), anti-SSB (\%22.0, 9/41), anti-CENP-B (\%12.2, 5/41) otoantikorları tespit edilmiştir (Tablo III). Anti-Ro52, SS'de sıklıkla anti-Ro60 (SS-A) ile kombinasyon halinde bulunmakta ve anti-Ro52, SS hastalarının yarısından fazlasında saptanmaktadır ${ }^{25,26}$. Çalışmamızda SS tanısı olan hastaların \%94.4 (17/18)'ünde antiRo52 antikoru saptanmış olup, \%61.1 (11/18)'inde ise anti-Ro52 ile anti-SSA birlikteliği görülmüştür. Ancak anti-Ro52 daha az oranda izole bir otoantikor olarak da bulunabilmektedir. İzole anti-Ro52 reaktivitesi öncelikle idiyopatik enflamatuvar miyopatiler (IIM), PBS, RA ve SS hastalarında karşımıza çıkmaktadır ${ }^{25,26}$. Hatta anti-Ro-52 antikorunun PBS ve SS birlikteliği için özgül bir belirteç olabileceği üzerinde durulmuştur ${ }^{22}$. Çalışmamızda da SS ve PBS birlikteliği olan hastaların tamamında anti-Ro52 antikoru saptanmıştır. PBS olgularının \%40.2'sinde anti-Ro52 antikorları saptanmıştır ${ }^{25}$. Anti-Ro52 aslında PBS'de en sık saptanan anti-ENA antikorlarından biridir. Granito ve arkadaşlarının çalışmalarında ${ }^{27}$ PBS hastalarında anti-Ro-52 antikoru \%28 oranında belirlenmiş olup, anti-SSA (\%2.8) ve anti-SSB (\%4.7) antikorlarından belirgin şekilde daha fazla oranda saptanmıştır.

Anti-Ro52 pozitif PBS hastalarının, anti-Ro52 negatif hastalara göre daha yüksek serum bilirubin, daha yüksek histolojik derece ve sekonder SS'ye sahip olma olasılığı daha yüksek olarak belirlenmiştir. OKH'nin seyrini büyük ölçüde kötüleştirdiği düşünülmektedir ${ }^{25-27}$. Fakat çalışmamızda anti-Ro52 antikoru pozitif PBS hastaları ile anti-Ro52 negatif PBS hastaları klinik bulgular, yaş, cinsiyet, biyokimyasal testler (ALT, AST, ALP, GGT, bilirubin), radyolojik bulgular (karaciğer heterojenitesi) ve siroz varlığı açısından karşılaştırılmış ve iki grup arasında istatistiksel olarak anlamlı bir fark saptanmamıştır.

Çalışmamızda PBS tanısı alan hastaların \%87.5 (70/80)'inde AMA pozitifliği, \%12.5 $(10 / 80)^{\prime}$ inde ise ANA pozitifliği (NM, ÇNN, sentromer gibi) saptanmıştır. PBS vakalarının yaklaşık \%25'i ANA pozitifliği ile tanınmaktadır ${ }^{22}$. AMA negatif PBS hastalarını belirlemede, NM (hedef antijenler: Lamin, Gp-210, Nükleoporin p62), ÇNN [Hedef antijenler; Sp-100, Promiyelositik lösemi proteini (PML)], ASA, anti-Ro-52 antikorlar oldukça önemlidir. NM boyanma paternindeki hedef antijen olan gp-210'a karşı antikorlar PBS hastalarının yaklaşık \%25'inde, ÇNN boyanma paternine neden olan hedef antijen sp100'e karşı antikorlar ise bu vakaların \%20-30'unda bulunmaktadır ve bunlar PBS için oldukça 
özgüldür ${ }^{7,27}$. PBS hastalarında ASA vakaların yaklaşık \%25'inde bulunabilmektedir ${ }^{7}$. ASA, CREST sendromu olarak bilinen sınırlı skleroderma için özgül kabul edilmekle birlikte, difüz skleroderma, SLE, RA, Raynoud fenomeni gibi hastalıklarda da pozitif olarak saptanabilmektedir. Literatürle uyumlu olarak, çalışma grubumuzda da PBS'li hastalarda ASA varlığı, sıklıkla sklerodermanın klinik bulgularıyla birlikte saptanmıştır ${ }^{28}$.

Bazı durumlarda, bu otoantikorların varlığı, sadece bir otoimmün hastalığı geliştirme riskini değil, aynı zamanda hastalığın prognozu hakkında da yol göstermektedir ${ }^{6,7}$. Tek başına AMA pozitifliği olan PBS hastaları (Grup 1) ile çoklu patern/otoantikorları olan hastaların (Grup 2) özellikleri, laboratuvar ve radyolojik bulgularını karşılaştırdığımızda; çoklu paterni/otoantikorları olan hastalarda (Grup 2) siroz varlığı ve USG'de karaciğer heterojenitesi Grup 1'e göre istatistiksel olarak anlamlı düzeyde yüksek bulunmuştur. Bu durum, farklı otoantikorların birlikteliğinin siroz gelişimi açısından bir risk faktörü olabileceğini düşündürmüştür. Grup 2'yi oluşturan hastaların \%45 (13/29)'inde antiRo-52 antikoru saptanmış olup bu hastaların yaklaşık yarısında siroz belirlenmiştir. PBS hastalarında AMA-M2'ye eşlik eden otoantikorlar ve klinik tabloya etkisinin araştırıldığı bir çalışmada, anti-Ro52 ve ASA'nın olguların \%17'sinde mevcut olduğu ve karaciğer hastalığı gelişimini etkilediği bildirilmiştir ${ }^{29}$. NM boyanmasına neden olan anti-gp210 antikorlarına sahip PBS hastalarının, karaciğer yetmezliği gelişme riski daha yüksek olup bu antikorların varlığı kötü prognozla ilişkilendirilmiştir. ASA varlığı portal hipertansiyon gelişimi açısından önemli bir risk faktörü olarak rapor edilmektedir ${ }^{7}$.

Görüldüğü gibi otoantikorlar PBS'de hem tanısal, hem de prognostik öneme sahiptir. Çalışmalar PBS tanısında AMA'ya odaklanmış olsa da, bugüne kadar PBS hastalarında 60'tan fazla otoantikor tespit edilmiştir. PBS gelişimi için birçok faktörün etkisi görülmektedir. Genetik yatkınlığı olan bireylerde, otoantikorların gelişimi ile birlikte çevresel faktörlerin de katkısıyla zamanla klinik hastalık tablosu oluşmaktadır ${ }^{7}$. Genetik faktörlerin yanı sıra, ek otoimmün hastalıkların varlığı ve sigara gibi faktörler PBS gelişimi ile en sık ilişkili faktörler olarak ilişkilendirilmiştir ${ }^{13}$. Sjögren sendromu, skleroderma, SLE ve RA gibi SORH ve Hashimoto tiroiditi, çölyak hastalığı gibi diğer ekstrahepatik otoimmün hastalıklar da dahil olmak üzere PBS'li hastaların \%40-70'inde otoimmün bozukluklar gözlenmektedir ${ }^{30}$. PBS $^{\prime}$ li hastaların yaklaşık \%60'ı rutin kontrollerde asemptomatik olduğundan, biyokimyasal testler ve otoantikorların saptanması bu hastaların tanısında erken ipuçları sağlar. Asemptomatik hastaların çoğu tanıdan 2-4 yıl sonra semptomatik hale gelir ${ }^{30}$.

Sonuç olarak, otoantikor testlerinin gelişimi, bunların yaygın olarak kullanılması erken tanı açısından son derece önemli basamaklardır. Otoantikorların tespiti sayesinde asemptomatik hastaların belirlenmesi, yakın takibi yapılabilmektedir. Laboratuvar uzmanı ile klinisyen işbirliği bu hastaların tanısında, yönetiminde, klinik hastalık tablosu oluşmadan tanınmasında kritik öneme sahiptir.

\section{ETIK KURUL ONAYI}

Bu çalışma, Balıkesir Üniversitesi Girişimsel Olmayan Araştırmalar Etik Kurulu onayı ile gerçekleştirildi (Tarih: 10.06.2020 ve Karar No: 2020/89). 


\section{ÇIKAR ÇATIŞMASI}

Yazarlar bu makale ile ilgili herhangi bir çıkar çatışması bildirmemişlerdir.

\section{KAYNAKLAR}

1. Arndtz K, Hirschfield GM. The pathogenesis of autoimmune liver disease. Dig Dis 2016; 34(4): 327-33.

2. Trivedi PJ, Hirschfield GM. Review article: overlap syndromes and autoimmune liver disease. Aliment Pharmacol Ther 2012; 36(6): 517-33.

3. Hov JR, Boberg KM, Karlsen TH. Autoantibodies in primary sclerosing cholangitis. World J Gastroenterol 2008; 14(24): 3781-91.

4. Sebode M, Weiler-Normann C, Liwinski T, Schramm C. Autoantibodies in autoimmune liver disease-clinical and diagnostic relevance. Front Immunol 2018; 9: 609.

5. Selmi C, De Santis M, Gershwin ME. Liver involvement in subjects with rheumatic disease. Arthritis Res Ther 2011; 13(3): 226.

6. Ma WT, Chang C, Gershwin ME, Lian ZX. Development of autoantibodies precedes clinical manifestations of autoimmune diseases: A comprehensive review. J Autoimmun 2017; 83: 95-112.

7. Hu CJ, Zhang FC, Li YZ, Zhang X. Primary biliary cirrhosis: what do autoantibodies tell us? World J Gastroenterol 2010; 16(29): 3616-29.

8. Csepregi A, Szodoray P, Zeher M. Do autoantibodies predict autoimmune liver disease in primary Sjögren's syndrome? Data of 180 patients upon a 5 year follow-up. Scand J Immunol 2002; 56(6): 623-9.

9. Arbuckle MR, McClain MT, Rubertone MV, Scofield RH, Dennis GJ, James JA, et al. Development of autoantibodies before the clinical onset of systemic lupus erythematosus. N Engl J Med 2003; 349(16): 1526-33.

10. Metcalf JV, Mitchison HC, Palmer JM, Jones DE, Bassendine MF, James OF. Natural history of early primary biliary cirrhosis. Lancet 1996; 348(9039): 1399-402.

11. Tsuji $K$, Watanabe $Y$, Kouno $H$, Aisaka $Y$, Masanaga $T$, Ishihara $H$, et al. A case of latent primary biliary cirrhosis. Hepatol Res 2004; 28(3): 166-9.

12. Mitchison HC, Bassendine MF, Hendrick A, Bennett MK, Bird G, Watson AJ, et al. Positive antimitochondrial antibody but normal alkaline phosphatase: is this primary biliary cirrhosis? Hepatology 1986; 6(6): $1279-84$.

13. Kim KA, Kim YS, Park SH, Chung WJ, Choi DH, Jang ES, et al. Environmental risk factors and comorbidities of primary biliary cholangitis in Korea: a case-control study. Korean J Intern Med 2021; 36(2): 313-21.

14. Efe C, Torgutalp M, Henriksson I, Alalkim F, Lytvyak E, Trivedi $H$, et al. Extrahepatic autoimmune diseases in primary biliary cholangitis: Prevalence and significance for clinical presentation and disease outcome. J Gastroenterol Hepatol 2021; 36(4): 936-42.

15. Selmi C, Generali E, Gershwin ME. Rheumatic manifestations in autoimmune liver disease. Rheum Dis Clin North Am 2018; 44(1): 65-87.

16. Wong GW, Heneghan MA. Association of extrahepatic manifestations with autoimmune hepatitis. Dig Dis 2015; 33(Suppl 2): 25-35.

17. Chowdhary VR, Crowson CS, Poterucha JJ, Moder KG. Liver involvement in systemic lupus erythematosus: case review of 40 patients. J Rheumatol 2008; 35(11): 2159-64.

18. Matsumoto T, Kobayashi S, Shimizu H, Nakajima M, Watanabe S, Kitami N, et al. The liver in collagen diseases: pathologic study of 160 cases with particular reference to hepatic arteritis, primary biliary cirrhosis, autoimmune hepatitis and nodular regenerative hyperplasia of the liver. Liver 2000; 20(5): 366-73.

19. Efe C, Ozaslan E, Nasiroglu N, Tunca H, Purnak T, Altiparmak E. The development of autoimmune hepatitis and primary biliary cirrhosis overlap syndrome during the course of connective tissue diseases: report of three cases and review of the literature. Dig Dis Sci 2010; 55(8): 2417-21. 
20. Hatzis GS, Fragoulis GE, Karatzaferis A, Delladetsima I, Barbatis C, Moutsopoulos HM. Prevalence and longterm course of primary biliary cirrhosis in primary Sjögren's syndrome. J Rheumatol 2008; 35(10): 2012-6.

21. Gershwin ME, Selmi C, Worman HJ, Gold EB, Watnik M, Utts J, et al. Risk factors and comorbidities in primary biliary cirrhosis: a controlled interview-based study of 1032 patients. Hepatology 2005; 42(5): 1194-202.

22. Sun Y, Zhang W, Li B, Zou Z, Selmi C, Gershwin ME. The coexistence of Sjögren's syndrome and primary biliary cirrhosis: a comprehensive review. Clin Rev Allergy Immunol 2015; 48(2-3): 301-15.

23. Assassi S, Fritzler MJ, Arnett FC, Norman GL, Shah KR, Gourh P, et al. Primary biliary cirrhosis (PBC), PBC autoantibodies, and hepatic parameter abnormalities in a large population of systemic sclerosis patients. I Rheumatol 2009; 36(10): 2250-6.

24. Akiyama Y, Tanaka M, Takeishi M, Adachi D, Mimori A, Suzuki T. Clinical, serological and genetic study in patients with CREST syndrome. Intern Med 2000; 39(6): 451-6.

25. Lee AYS. A review of the role and clinical utility of anti-Ro52/TRIM21 in systemic autoimmunity. Rheumatol Int 2017; 37(8): 1323-33.

26. Defendenti C, Atzeni F, Spina MF, Grosso S, Cereda A, Guercilena G, et al. Clinical and laboratory aspects of Ro/SSA-52 autoantibodies. Autoimmun Rev 2011; 10(3): 150-4.

27. Granito A, Muratori P, Muratori L, Pappas G, Cassani F, Worthington J, et al. Antibodies to SS-A/Ro-52kD and centromere in autoimmune liver disease: a clue to diagnosis and prognosis of primary biliary cirrhosis. Aliment Pharmacol Ther 2007; 26(6): 831-8.

28. Mackay IR, Whittingham S, Fida S, Myers M, Ikuno N, Gershwin ME, et al. The peculiar autoimmunity of primary biliary cirrhosis. Immunol Rev 2000; 174: 226-37.

29. Defendenti C, Bollani S, Munegato G, Saibeni S, Sofia M, Bruno S, et al. Local experience on frequency and significance of immunological overlap in the field of primary biliary cirrhosis (PBC). Microbiologia Medica 2008; 23(2): 183-5.

30. Pullen R. A clinical review of primary biliary cholangitis. Gastroenterol Nurs 2020; 43(2): E48-E55. 